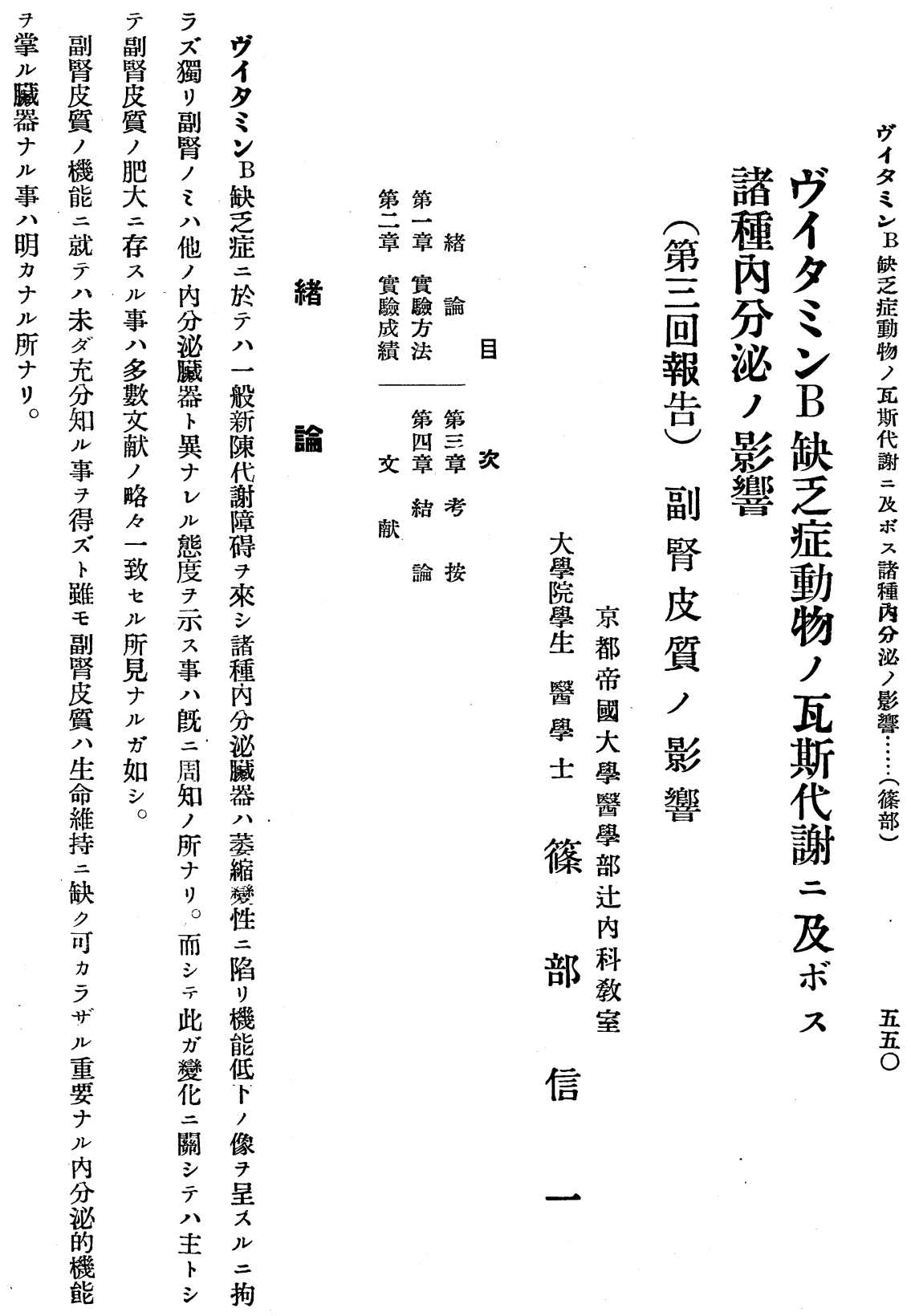




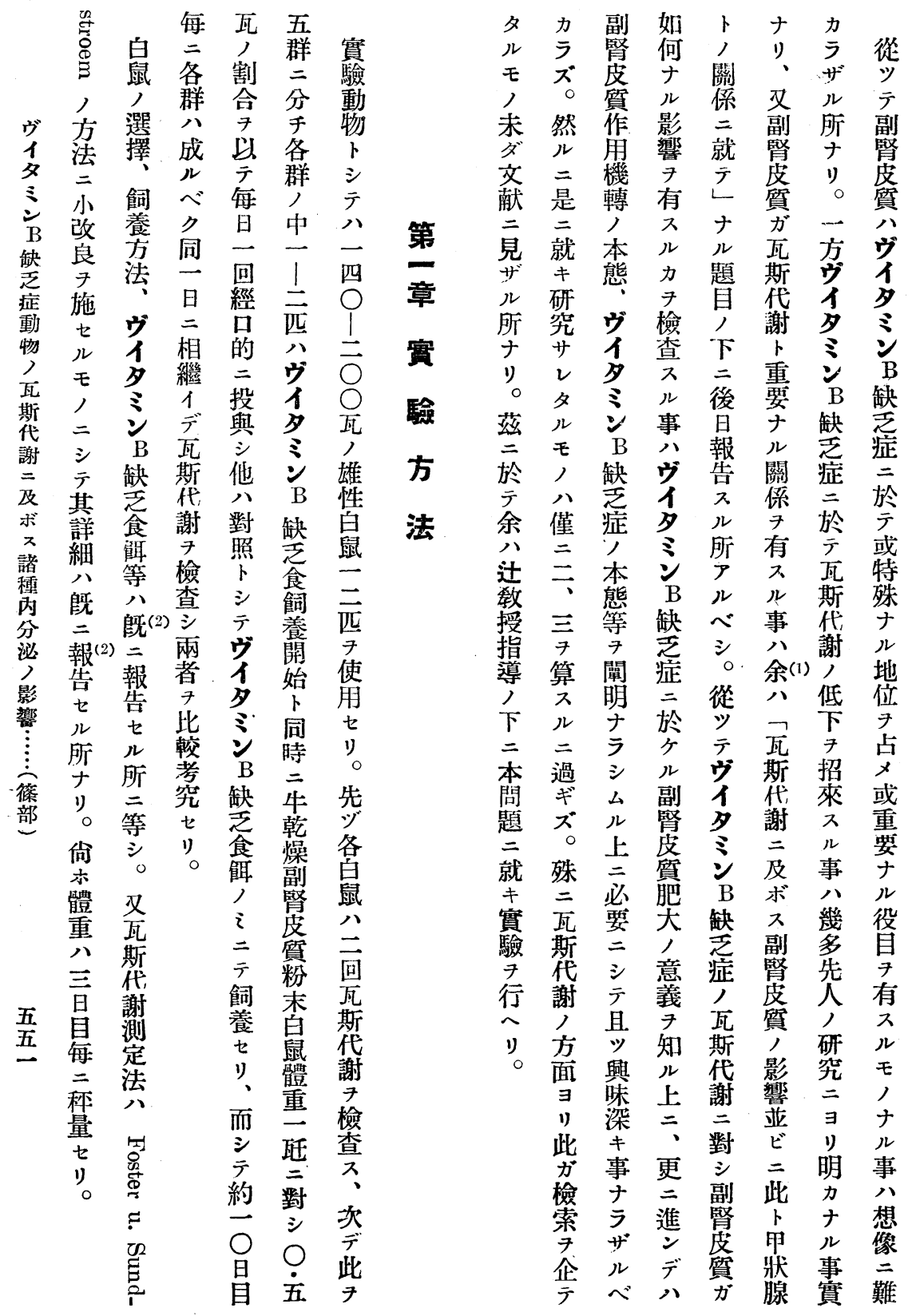




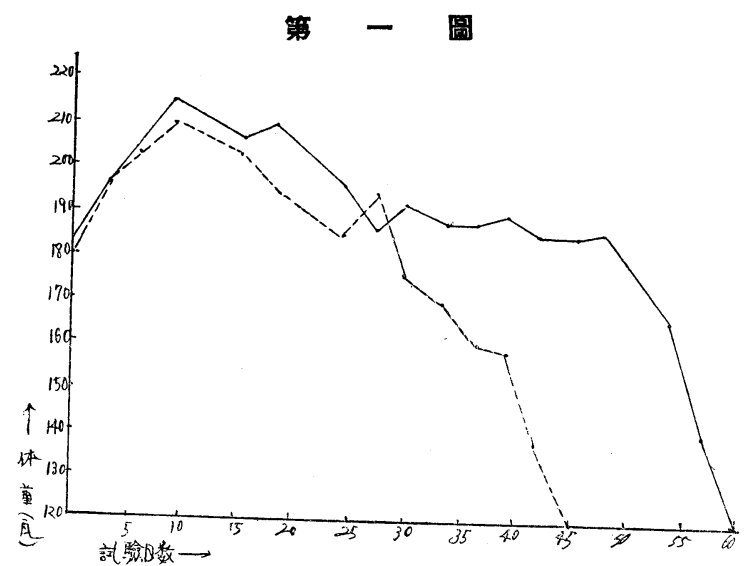

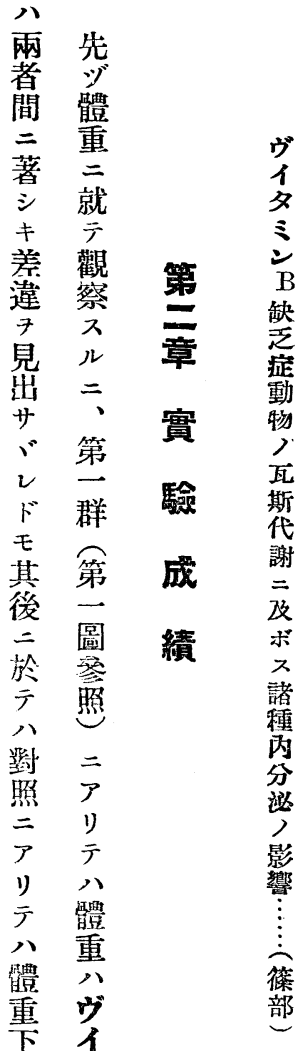

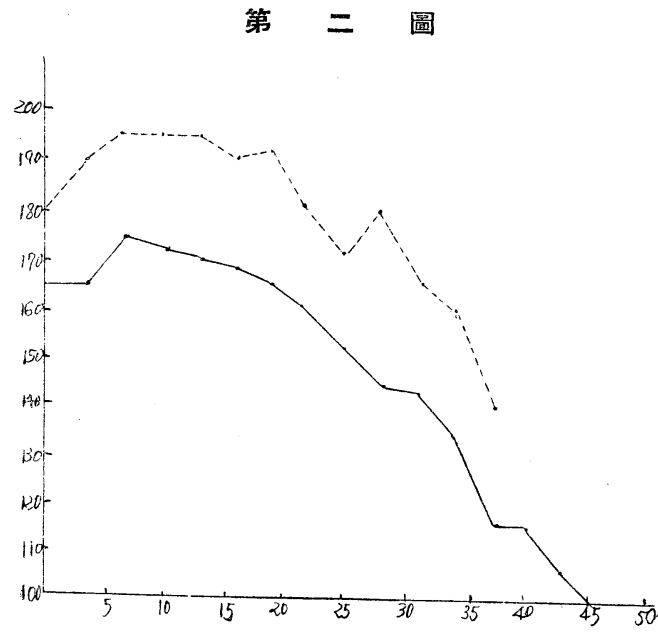

ヴイタミンB缺乏食鸰養卜同時二副腎 皮質粉末每䣶 0.5 瓦試食白鼠

- - ヴイタミン B 缺乏食飼養白鼠

一一ヴイタミンB缺乏食飼養ト同時二副腎 皮質粉末每的 0.5 瓦試食白鼠

- - ヴイタミン B 缺乏食飼養白鼠

吾 

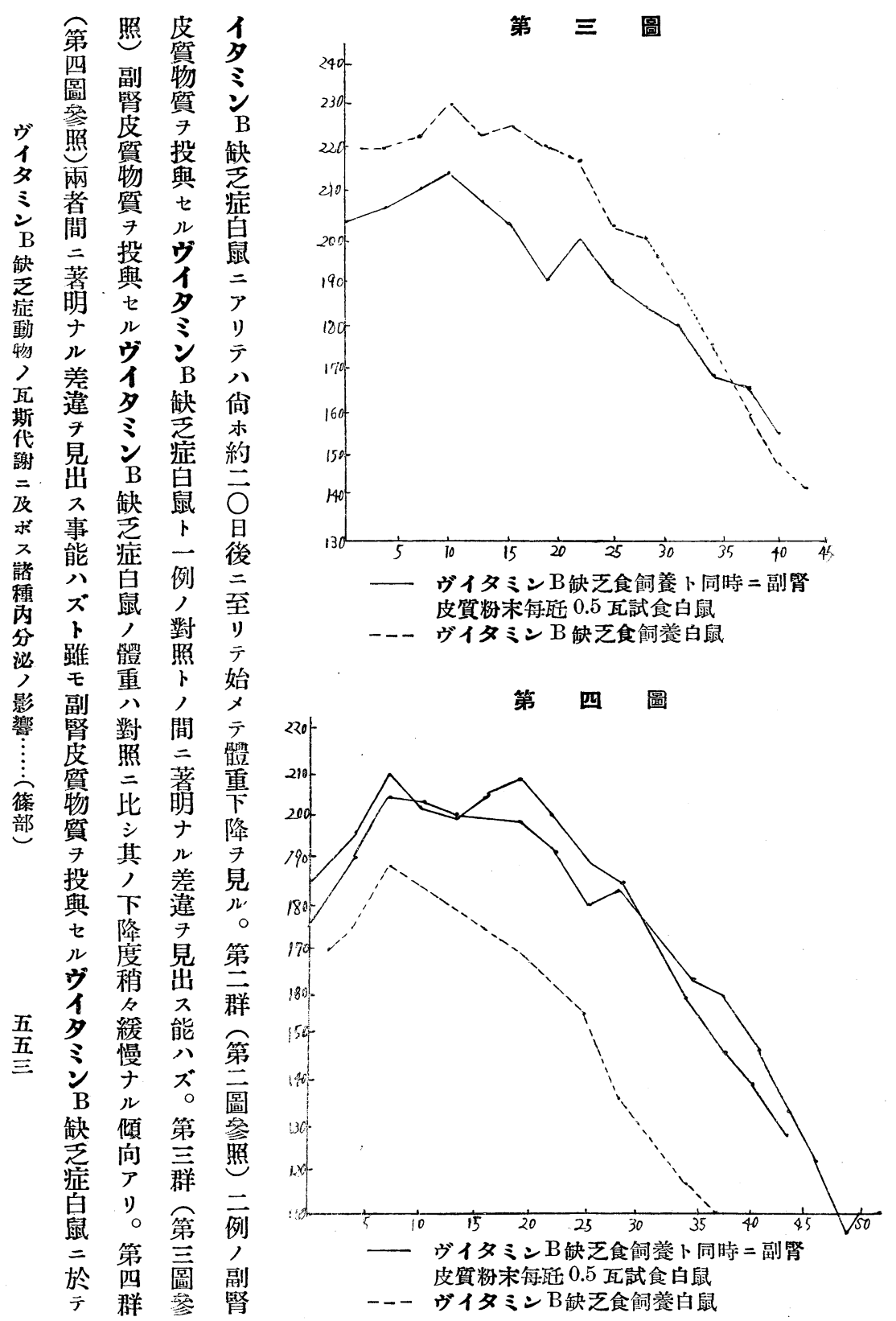


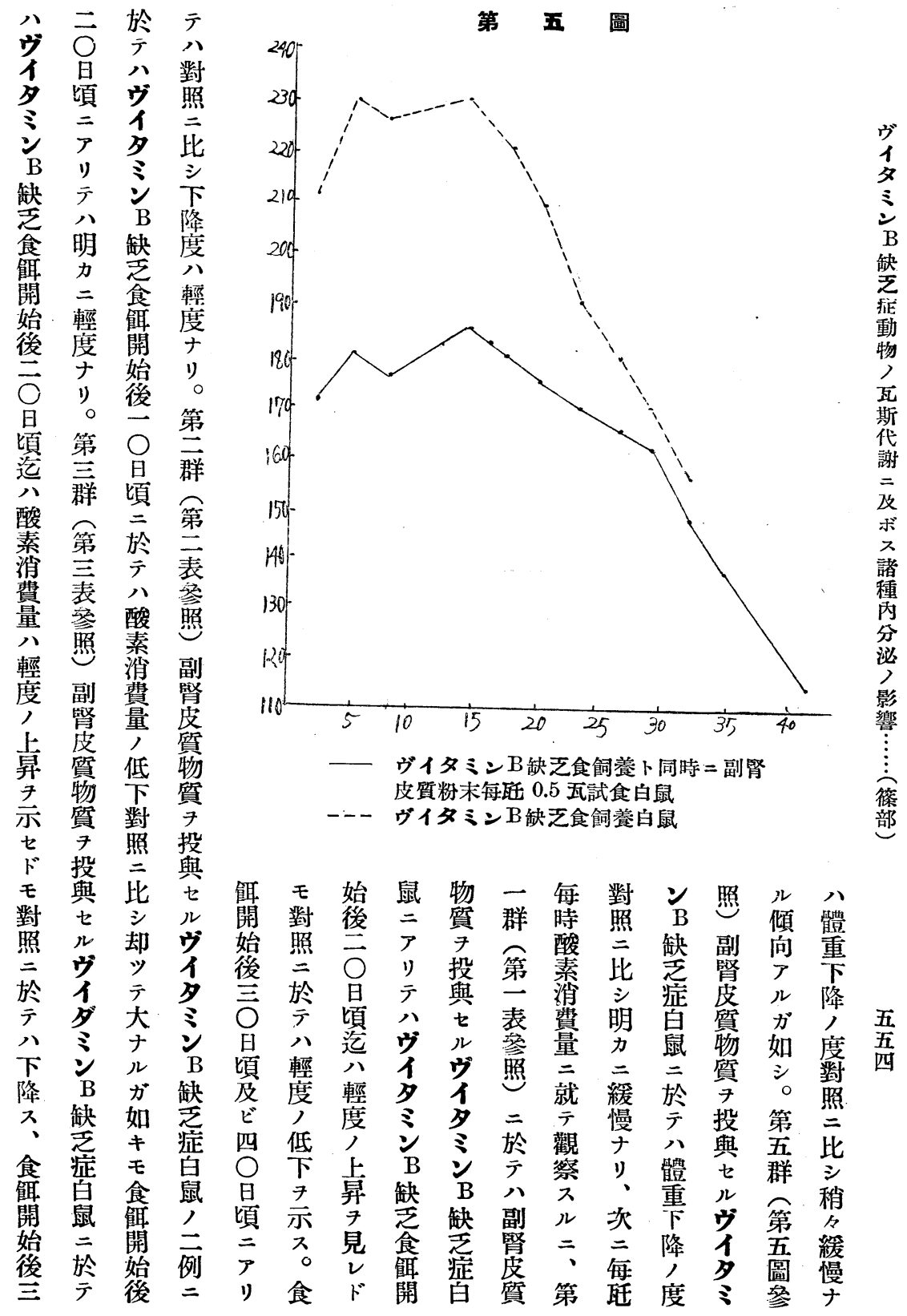




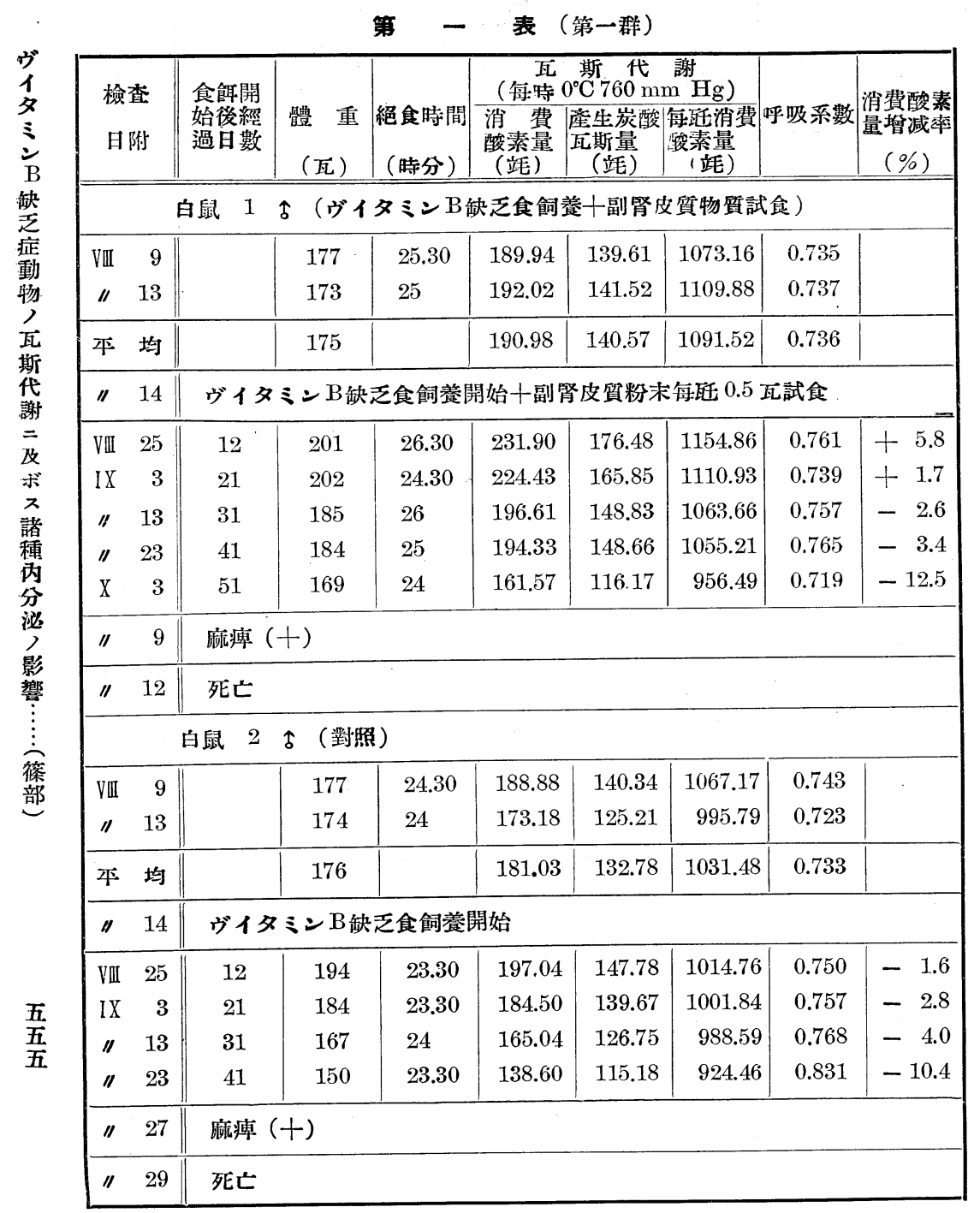




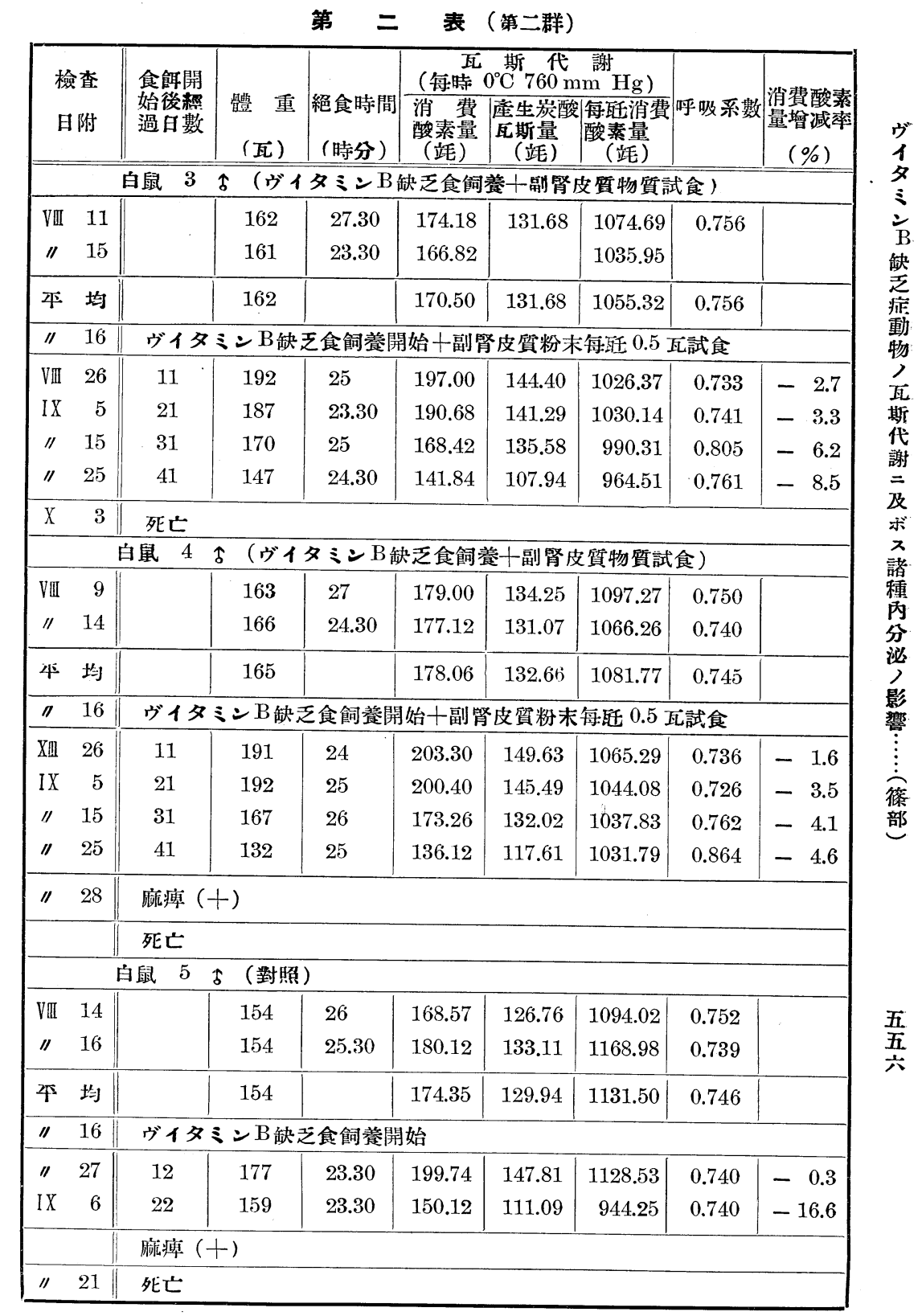




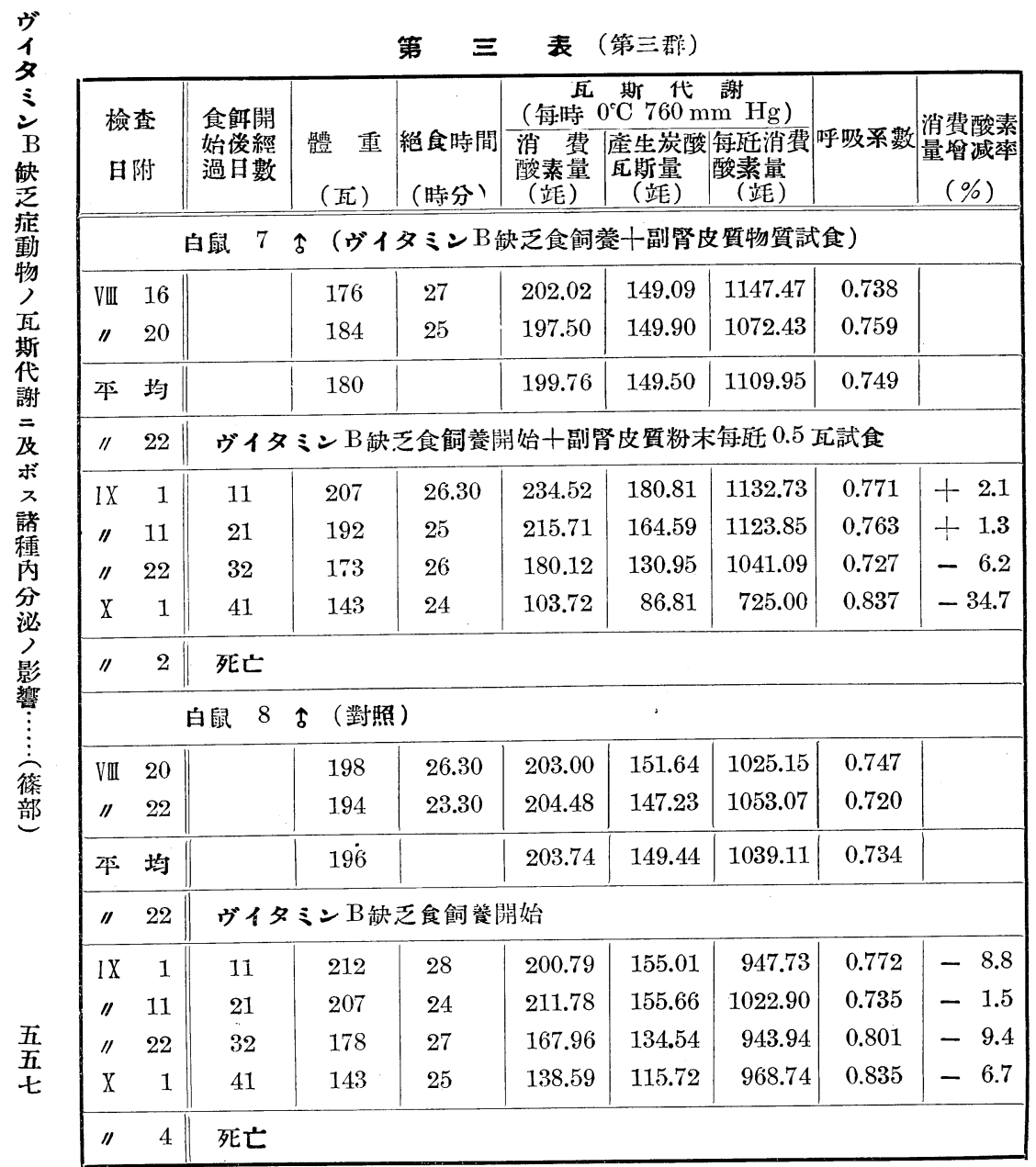


第 四表（第四群）

\begin{tabular}{|c|c|c|c|c|c|c|c|c|}
\hline $\begin{array}{l}\text { 检查 } \\
\text { 日附 }\end{array}$ & $\begin{array}{l}\text { 食餌開 } \\
\text { 始後經 } \\
\text { 過日數 }\end{array}$ & $\begin{array}{l}\text { 體 重 } \\
\text { (酉) } \\
\end{array}$ & $\left|\begin{array}{c}\text { 絕食時間 } \\
\text { (時分) }\end{array}\right|$ & 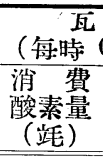 & $\begin{array}{c}\text { 斯 代 } \\
0^{\circ} \mathrm{C} 760 \mathrm{~m} \\
\begin{array}{c}\text { 童生炭酸 } \\
\text { 斯量 } \\
\text { (竨) }\end{array} \\
\end{array}$ & $\begin{array}{l}\text { 謝 } \\
\text { m } \mathrm{Hg} \text { ) } \\
\text { 每䂡消費 } \\
\text { 酸素量 } \\
\text { (竓) } \\
\end{array}$ & 呼吸系數 & $\begin{array}{c}\text { 消費酸素 } \\
\text { 量增减率 } \\
(\%) \\
(\%)\end{array}$ \\
\hline \multicolumn{9}{|c|}{ 白鼠 9 占（ヴイタミンB缺乏食創養十副腎皮質物質試食） } \\
\hline VIII 22 & & 143 & 26.30 & 171.66 & 129.26 & 1196.41 & 0.753 & \\
\hline " 29 & & 152 & 27 & 178.32 & 132.85 & 1173.35 & 0.745 & \\
\hline 平 均 & & 148 & & 174.74 & 131.06 & 1184.88 & 0.749 & \\
\hline " 31 & \multicolumn{8}{|c|}{ （ヴイタミンB缺え食飼羪開始十副腎庆質粉末每䏕 0.5 瓦試食） } \\
\hline IX 10 & 11 & 164 & 26 & 190.68 & 153.12 & 1163.15 & 0.803 & -1.9 \\
\hline " 20 & 21 & 152 & 25 & 180.08 & 135.42 & 1184.93 & 0.752 & \pm 0 \\
\hline " 29 & 30 & 135 & 25 & 162.89 & 125.75 & 1207.01 & 0.772 & +1.9 \\
\hline X 10 & 41 & 109 & 23 & 107.85 & & .988 .98 & & -16.5 \\
\hline " 13 & 44 & 109 & 21 & 109.76 & & 1006.50 & & -15.0 \\
\hline " 15 & \multicolumn{8}{|c|}{ 麻㾝 $(+)$} \\
\hline "I 16 & \multirow{2}{*}{\multicolumn{8}{|c|}{$\begin{array}{l}\text { 死亡 } \\
\text { 白鼠 } 10 \text { 古 (對照) }\end{array}$}} \\
\hline 白鼠 10 古（對照） & & & & & & & & \\
\hline VIII $\quad 23$ & & 153 & 25.30 & 179.34 & 136.84 & 1172.88 & 0.763 & \\
\hline " 29 & & 164 & 25 & 198.36 & & 1210.00 & & \\
\hline 平均 & & 159 & & 188.85 & 136.84 & 1191.44 & 0.763 & \\
\hline " 31 & \multicolumn{8}{|c|}{ ヴイタミンB缺乏食飼養開始 } \\
\hline IX 10 & 11 & 181 & 25 & 196.60 & 139,98 & 1085.23 & 0.712 & -8.9 \\
\hline /I 29 & 30 & 167 & 23.30 & 172.20 & 136.38 & 1019.42 & 0.792 & -14.4 \\
\hline X 8 & \multicolumn{8}{|l|}{ 死亡 } \\
\hline
\end{tabular}


第五表（第后群）

\begin{tabular}{|c|c|c|c|c|c|c|c|c|}
\hline $\begin{array}{l}\text { 檢査 } \\
\text { 日附 }\end{array}$ & $\begin{array}{l}\text { 食餌開 } \\
\text { 始後經 } \\
\text { 過日數 }\end{array}$ & $\begin{array}{c}\text { 體 重 } \\
\text { (瓦) }\end{array}$ & 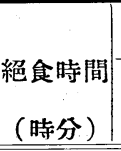 & $\begin{array}{c}\text { 氐 } \\
\text { (每侍 } \\
\text { 消 費 } \\
\text { 酸素量 } \\
\text { (竓) } \\
\end{array}$ & 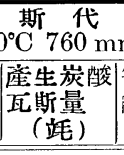 & 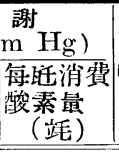 & 呼吸系數 & $\begin{array}{c}\text { 消費酸素 } \\
\text { 量增減钎 } \\
(\%)\end{array}$ \\
\hline \multicolumn{9}{|c|}{ 白鼠 11 占（ヴイタミンB缺乏食袔養十副腎皮質物貿試食） } \\
\hline VIII 30 & & 154 & 25 & 175.46 & 131.24 & 1138.74 & 0.748 & \\
\hline IX 2 & & 156 & 26.30 & 176.24 & 132.00 & 1129.70 & 0.748 & \\
\hline 平均 & & 155 & & 175.85 & 131.62 & 1134.22 & 0.749 & \\
\hline 112 & \multicolumn{8}{|c|}{ ヴイタミンB缺乏食飼養開始十副腎皮質粉末每瓦 0.う 瓦試食 } \\
\hline " 12 & 11 & 177 & 26 & 192.48 & 142.44 & 1087.51 & 0.740 & -4.1 \\
\hline " 22 & 21 & 172 & 24 & 177.00 & 132.40 & 1028.37 & 0.748 & -9.3 \\
\hline $\mathrm{X} \quad 2$ & 31 & 151 & 24.30 & 162.36 & 114.63 & 1074.82 & 0.706 & -5.2 \\
\hline "I 13 & \multicolumn{8}{|c|}{ 麻痺 $(+)$} \\
\hline II 15 & \multicolumn{8}{|l|}{ 死亡 } \\
\hline \multicolumn{9}{|c|}{ 白鼠 12 个 （對照） } \\
\hline VIII $\quad 29$ & & 188 & 24.30 & 206.62 & 149.59 & 1099.22 & 0.724 & \\
\hline IX 2 & & 197 & 23.30 & 225.32 & 162.91 & 1144.63 & 0.723 & \\
\hline 本 均 & & 193 & & 215.97 & 156.25 & 1121.93 & 0.724 & \\
\hline "I & \multicolumn{8}{|c|}{ ヴイタミンB缺乏食筒養開始 } \\
\hline " 12 & 11 & 225 & 24.30 & 233.70 & 168.97 & 1037.63 & 0.723 & -7.5 \\
\hline " 22 & 21 & 200 & 25 & 205.44 & 153.05 & 1027.20 & 0.745 & -8.5 \\
\hline $\mathrm{X} \quad 2$ & 31 & 156 & 23.30 & 158.70 & 119.98 & 1017.27 & 0.756 & -9.4 \\
\hline 11 & \multicolumn{8}{|l|}{ 死亡 } \\
\hline \multicolumn{9}{|c|}{ 白鼠 6 占（對照） } \\
\hline VIII 21 & & 146 & 27.30 & 166.20 & 125.15 & 1138.47 & 0.753 & \\
\hline II 23 & & 142 & 24.30 & 170.54 & 124.84 & 1200.60 & 0.732 & \\
\hline 平 坞 & & 144 & & 168.37 & 125.00 & 1169.54 & 0.743 & \\
\hline II 24 & \multicolumn{8}{|c|}{ ヴイタミン B 缺乏食飼養開始 } \\
\hline IX 3 & 11 & 157 & 25.30 & 170.36 & 133.22 & 1085.19 & 0.782 & -7.3 \\
\hline / 13 & 21 & 145 & 27 & 147.96 & 115.41 & 1020.92 & 0.780 & -12.7 \\
\hline " 23 & 31 & 132 & 26 & 143.78 & 113.44 & 1089.85 & 0.789 & -6.8 \\
\hline$X \quad 3$ & 41 & 119 & 25 & 133.01 & 108.80 & 1117.28 & 0.818 & -4.5 \\
\hline " 13 & 51 & 107 & 20.30 & 119.16 & 97.47 & 1114.15 & 0.818 & -4.8 \\
\hline II 20 & \multicolumn{8}{|c|}{ 麻㽻 $(+)$} \\
\hline II 22 & \multicolumn{8}{|l|}{ 死亡 } \\
\hline
\end{tabular}




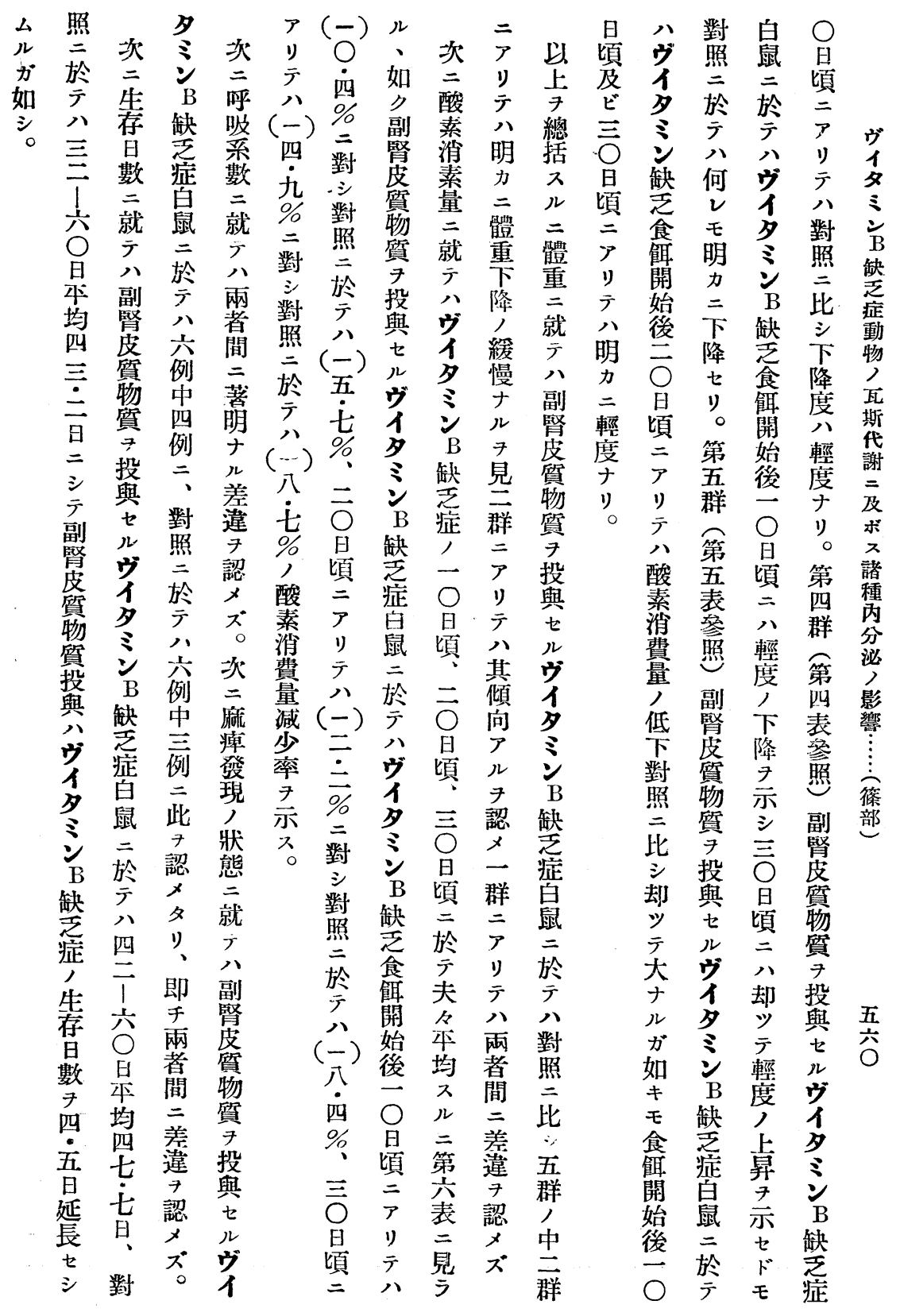




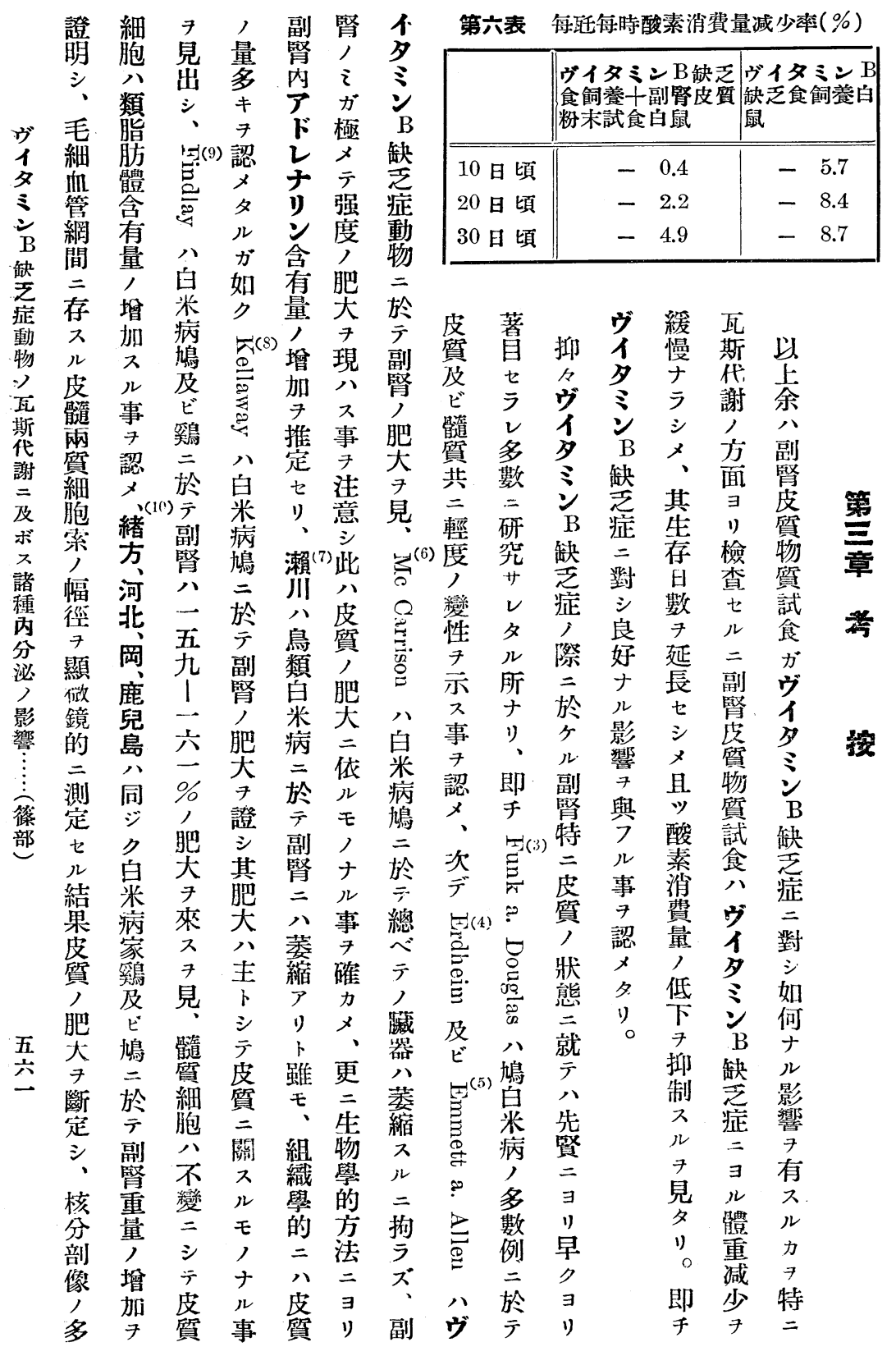




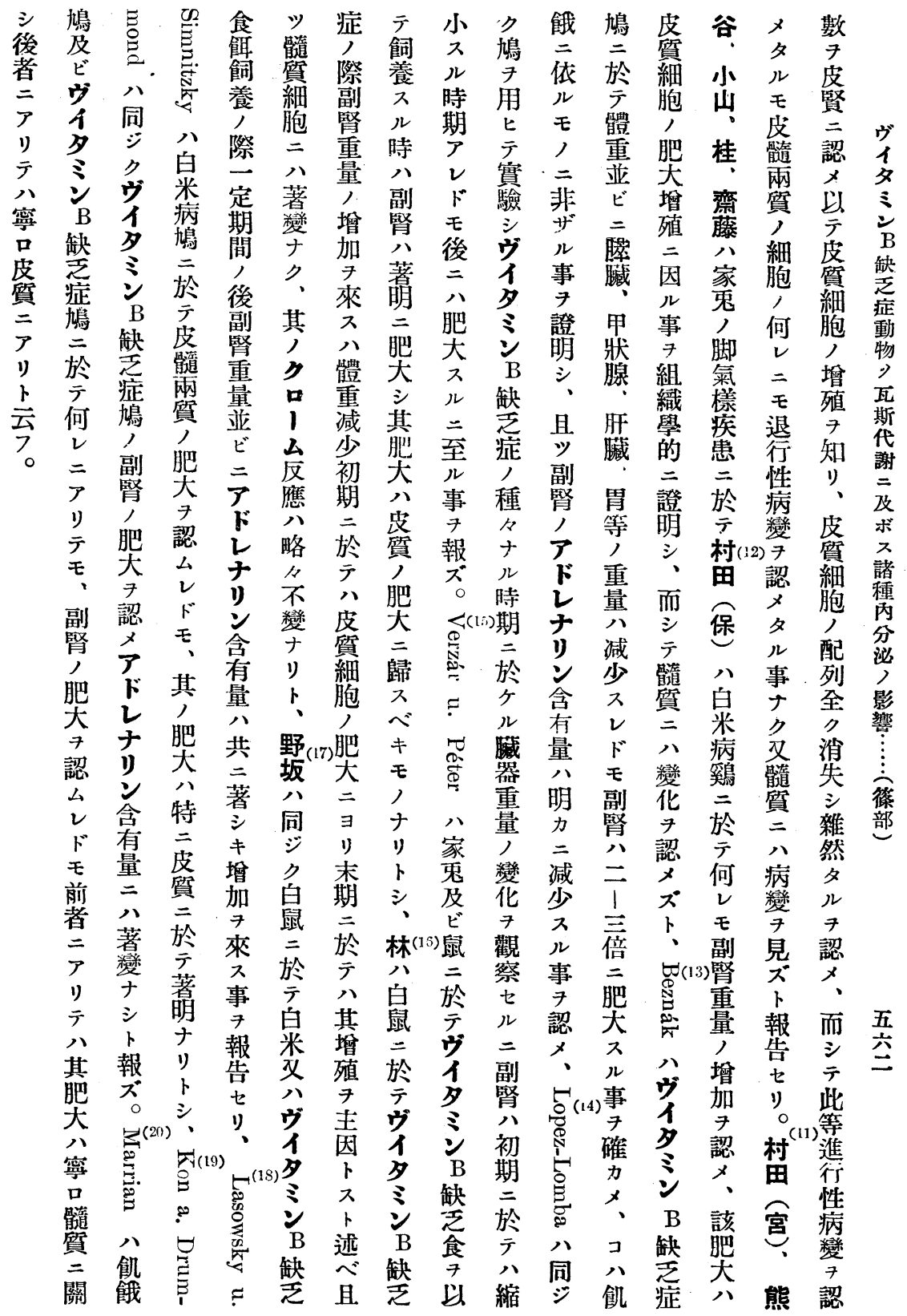




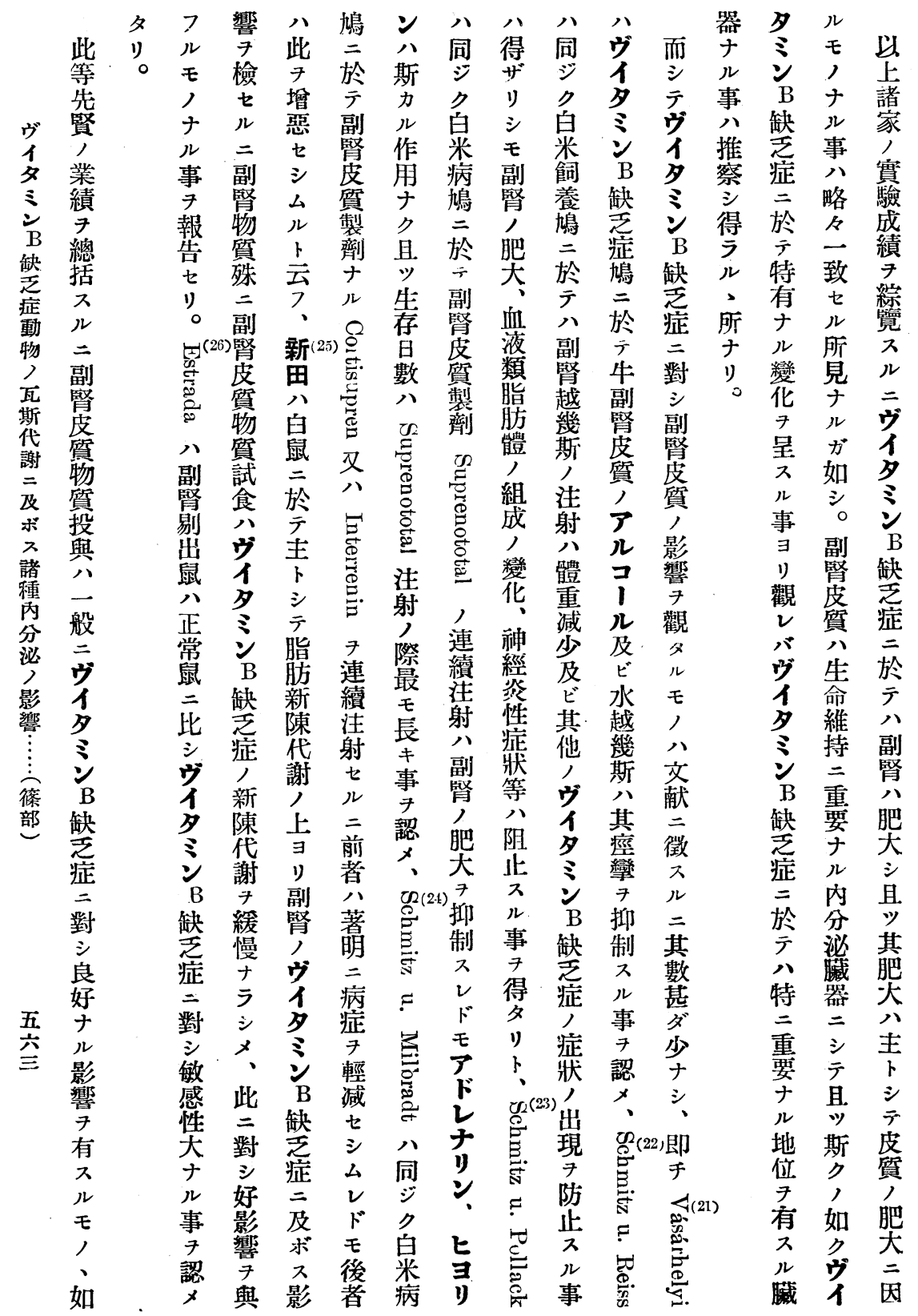




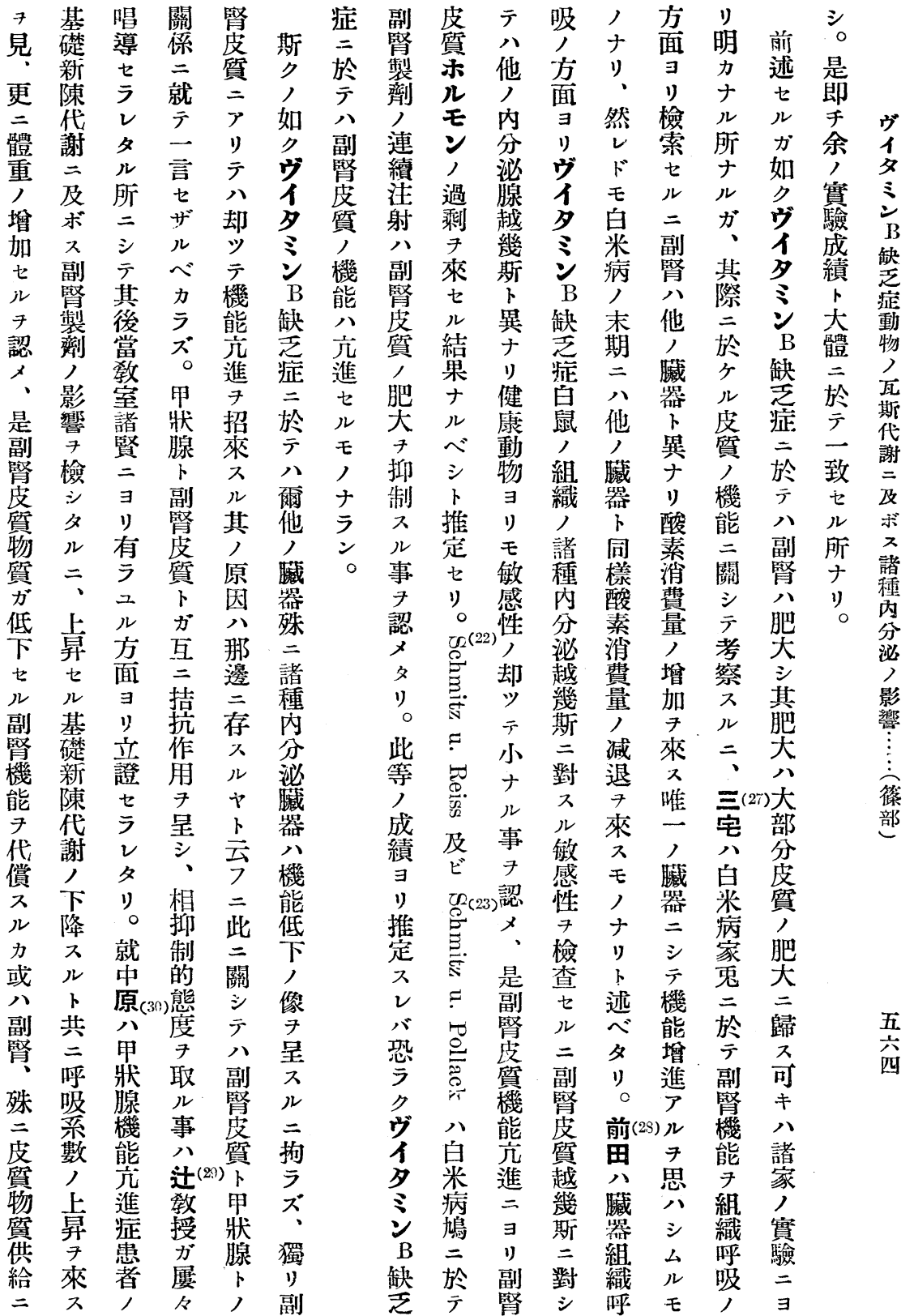




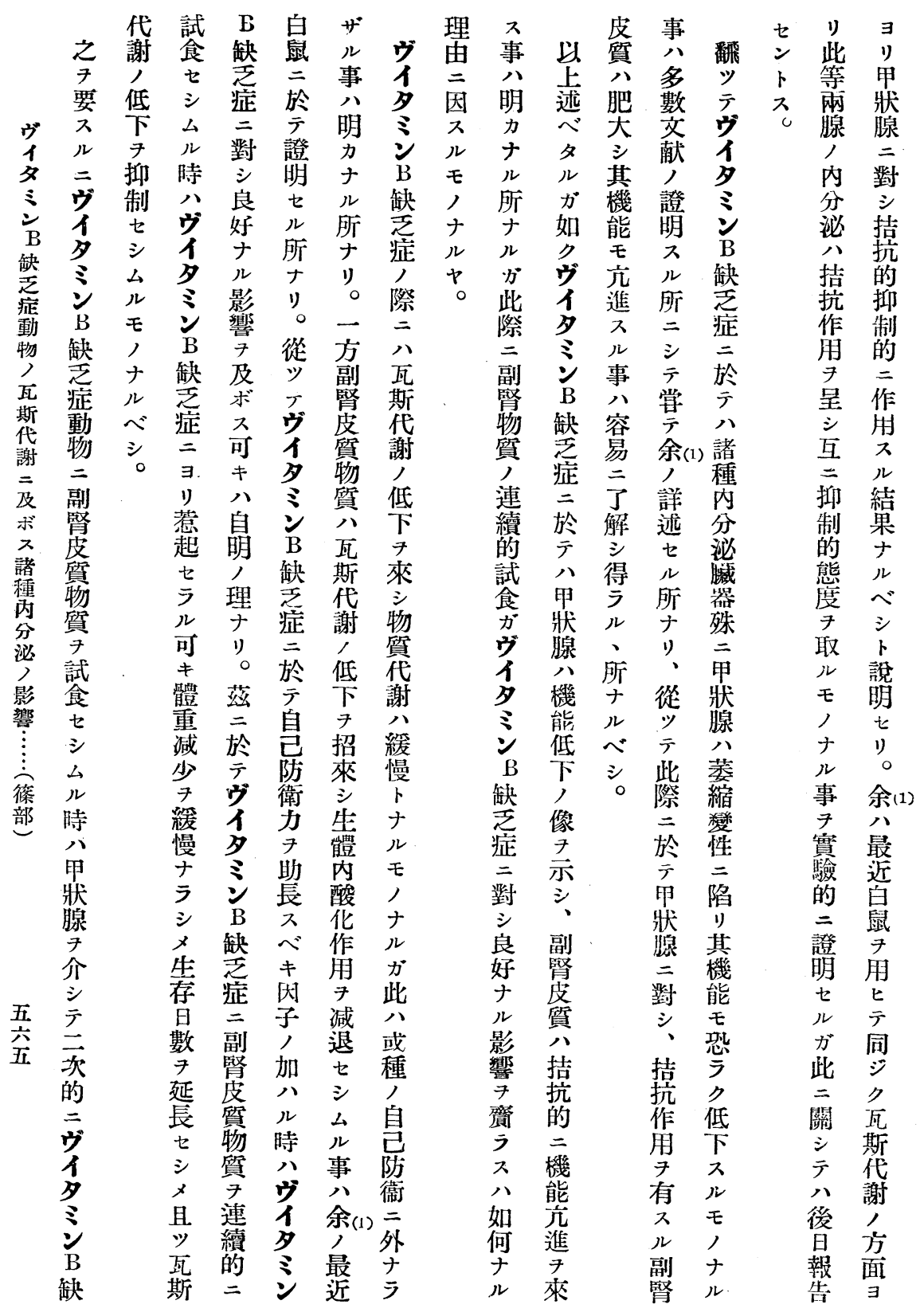




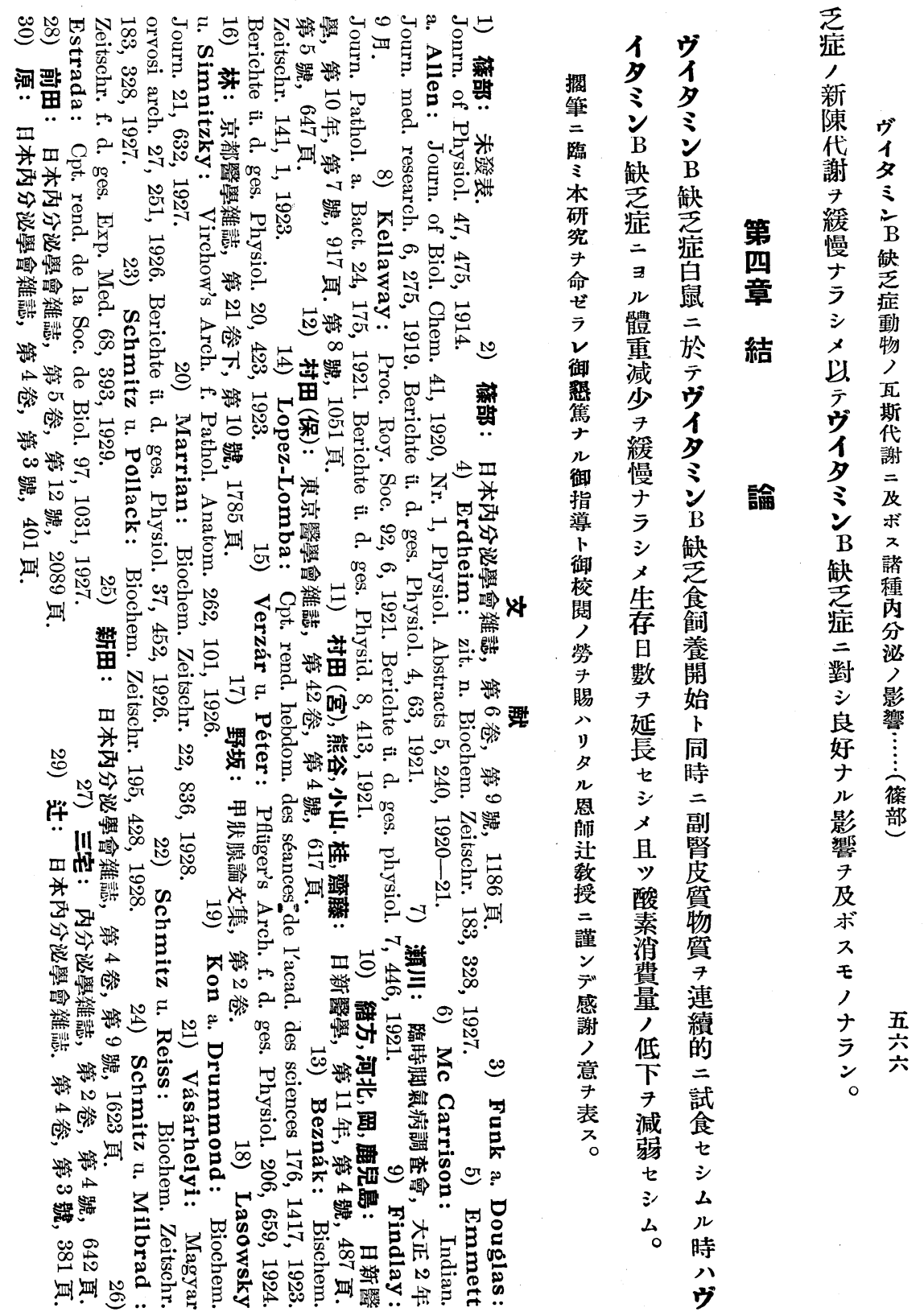


3) Wenn man Ratten etwa zehn Tage lang vitaminfrei gefüttert und ihnen gleichzeitig Insulin injiziert hat, so steigt der Sauerstoffverbrauch in leichtem Masse an, während der der Kontrolltiere abnimmt, und die respiratorischen Quotienten zeigen keine deutliche Veränderung den Kontrolltieren gegenüber. Wenn man Ratten etwa zwanzig Tage lang vitaminfrei gefüttert und ihnen gleichzeitig Insulin injiziert hat, so sinkt der Sauerstoffverbrauch weniger als bei der Kontrolle, und die respiratorischen Quotienten zeigen keine Veränderungen den Kontrolltieren gegenüber. Wenn man Ratten etwa dreissig Tage lang vitaminfrei gefüttert und ihnen gleichzeitig Insulin injiziert hat, so sinkt der Sauerstoffverbrauch stärker als, bei den Kontrolltieren, und die respiratorischen Quotienten neigen zu einem etwas stärkeren Ansteigen als bei den Kontrollieren.

4) Bei den normalen weissen Rattén steigt zunächst der Sauerstoffverbrauch nach der Insulininjektion (0.15-0.6 kl. E. H. per Kilogramm intraperitoneal) an, um dann wieder herabzugehen, und die respiratorischen Quotienten zeigen im allgemeinen Neigung zur Steigerung. Die steigeruug des Sauerstoffverbrauches und des respiratorischen Quotienten der B-avitaminösen weissen Ratten durch einmalige Insulininjektion (0.5-0.6 kl. E. H. per Kilogramm intraperitoneal) ist grösser als die Steigerung durch dieselbe Injektion bei derselben Ratte bei der Fütterung mit vitaminhaltiger Kost. Der Sauerstoffverbrauch und der respiratorische; Quotient neigen mit dem Fortschreiten der Avitaminose immer mehr zur Zunahme.

(Autoreferat)

\section{Studien über den Einfluss der verschiedenen innersekretorischen Drüsen auf den Gas- wechsel der B-avitaminösen Tiere. \\ III. Mitteilung. Ueber den Einfluss der Nebennierenrinde.}


Von

Dr. S. Shinobe.

(Aus der I. med. Klinik de: Kaiserl. Univers. zu Kyoto, Japan.

Direktor: Prof. Dr. K. Tsuji.)

Der Verfasser stellte dieses Experiment an männlichen weissen Ratten an, um festzustellen, wie Nebennierenrinde den Gaswechsel bei B-Avitaminosen beeinflusst. Die Gaswechselbestimmung wurde nach der modifizierten Foster-Sundstroemschen Methode ausgeführt.

Die Resultate sind die folgenden :

Wenn man die Ratten mit vitaminfreier Kost und mit getrocknetem Nebennierenrindenpulver füttert, so wird die Körpergewichtsabnahme durch Avitaminose verlangsamt, die Lebensdauer verlängert und die Herabsetzung des Sauerstoffverbrauches verhindert.

(Autoreferat)

\title{
Ueber den Einfluss des Schwefels auf den Gaswechsel und die Beziehung zwischen Schwefel und Schilddrüse in Bezug auf denselben.
}

\author{
Von
}

Dr. S. Shinobe.

(Aus der I. med. Klinik der Kaiserl. Univers. zu Kyoto, Japan. Direktor: Prof. Dr. K. Tsuji.)

Dieses Experiment wurde bei männlichen weissen Ratten vorgenommen. Die Gaswechselbestimmung wurde nach der modifizierten Foster-Sundstroemschen Methode ausgeführt.

Die Resultate sind wie folgt:

1) Wiederholte subkutane Schwefelelekroidinjektion an den gesunden weissen Ratten zeigt die Neigung eine Verminderung des 